\title{
A STUDY ON SEXUAL DIMORPHISM OF THE HUMERUS IN CENTRAL
} GUJARAT

\author{
Hetal V. Vaishnani ${ }^{* 1}$, A.R.Gandotra ${ }^{2}$, G.V.Shah ${ }^{3}$.
}

${ }^{{ }_{1}}$ Associate Professor, Dept. of Anatomy, Smt.B.K.Shah Medical institute \& Research centre, Sumandeep Vidyapeeth, Piparia, Vadodara, Gujarat, India.

${ }^{2}$ Prof. \& HOD, Dept. of Anatomy, Smt.B.K.Shah Medical institute \& Research centre, Sumandeep Vidyapeeth, Piparia, Vadodara, Gujarat, India.

${ }^{3}$ Dean \& Professor, Dept. of Anatomy, Smt.B.K.Shah Medical institute \& Research centre, Sumandeep Vidyapeeth, Piparia, Vadodara, Gujarat, India.

\section{ABSTRACT}

Introduction: Anthropometric techniques have been commonly used to estimate the stature from bones and play an important role in identifying unknown bodies by anthropologists and anatomists for over hundred years. Forensic experts and anthropologists often have a task of identification of sex of skeletal remains which is an aspect of the biological profile of an individual. The humerus is among the long bones which have been found to remain in better condition after the death of the individual and can be used for analysis of sex of the individual.

Aim: To assess the role of multivariate analysis of humerus metric parameters for sex differentiation of adult male and female humerus.

Materials and Methods: This cross-sectional observational study was done on 102 adult human humeri of known sex available in the bone bank of the Department of Anatomy, Smt.B.K.Shah Medical institute \& Research Centre Piparia, Vadodara, Central Gujarat, India

Results: A total 102 Adult humerus 64 Male and 38 Female were studied in present study. Twenty five measurements were taken from each humerus. The accuracy rate for sex determination by discriminant analysis using the five parameters i.e., weight, total length, vertical diameter of head, transverse diameter of the head and the circumference of midshaft of the humerus.

KEYWORDS: Humerus bone; Morphometry, Sexual dimorphism.

Address for Correspondence: Dr.HetalVaishnani, Associate Professor, Dept. of Anatomy, Smt.B.K.Shah Medical institute \& Research centre, Sumandeep Vidyapeeth,Piparia, PIN : 391760 Vadodara, Gujarat, India. M: 9978906569 E-Mail:drhetal24@gmail.com

Access this Article online

Quick Response code

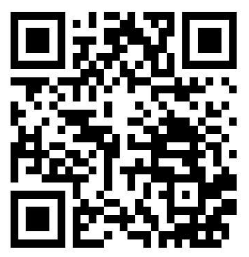

DOI: 10.16965/ijar.2019.200
Journal Information

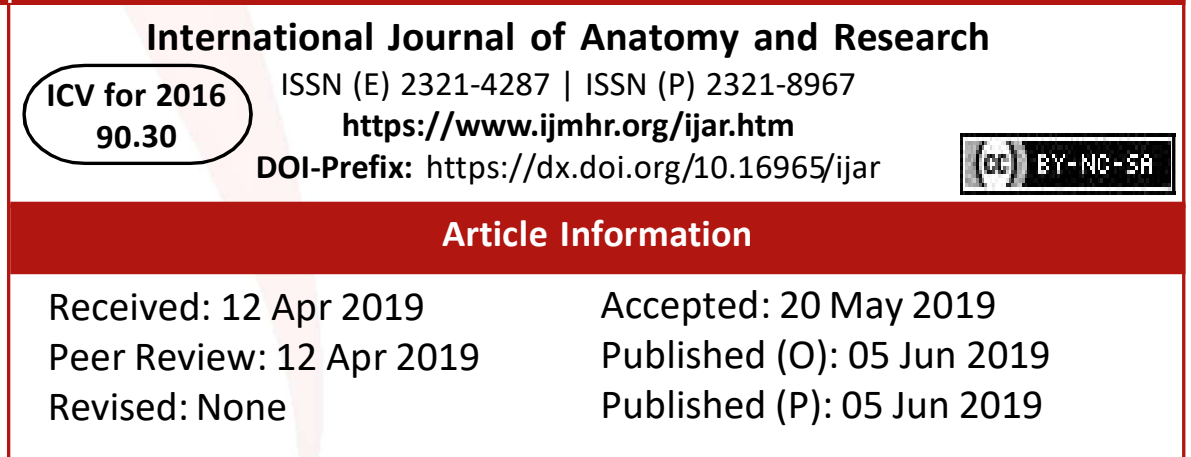

\section{INTRODUCTION}

Determination of sex is an important first step in the development of the biological profile in human osteology, whether analyzing a forensic case or an archaeological population. Without an accurate determination of sex, we cannot accurately estimate age at death, as rates of growth, development and degeneration vary by sex as well as population.
The determination of sex of an individual is primary criteria of identification. The osseous skeleton is the only structure to resist this effect for long time. The osseous skeleton therefore maintains its morphological features long after the soft tissue have been destroyed [1]. Identifying the sex of a body and estimating the body's stature are considered the most importantfactors in establishing the identity of 
indefinite dead bodies, parts of bodies, or even skeletal fragments [2].

Many researchers studied the sexual dimorphism of adult skeletons [3-5] using the dimensions of the skull, face $[6,7]$, long bones $[8,9]$, hands, feet $[10,12]$, and pelvis $[13,14]$. Scholars proved that a specific study is needed for each population to gain accurate results for the sexual identification of a skeleton [15]. Discriminant function analysis had been used to estimate the sex from bones if they are suspected to be sexually dimorphic $[16,17]$.The pelvis was considered to be the most accurate bone for sexdetermination, as it allows for parturition in females.

The humerus is the bone of the arm, and is the strongest and longest bones of the upper extremity. It presents upper and lower ends, and an intervening shaft [18]. Nutrient foramen is an opening in the shaft of humerus. The nutrient artery enters through nutrient foramen through cortex into the medullary cavity of the humerus [19].

Almost all bones of the human skeleton show some degree of sexual dimorphism. The accuracy of sex determination depends on the type and condition of the bone, age of the subject, the degree of fragmentation of the bones and biological variability. Obvious sex differences do not become apparent until after puberty, though specialized measurements on the pelvis can indicate sex even in fetal material. It is recognized that long bone cross-sectional area is greater in males as compared to females which reflects more rapid periosteal bone growth in boys [19].

\section{MATERIALS AND METHODS}

This cross-sectional observational study was done on 102 adult human humeri of known sex available in the bone bank of the Department of Anatomy, Smt.B.K.Shah Medical institute \& Research Centre Piparia, Vadodara, Central Gujarat, India.The convenience sample may not be representative of reference population from the region, it provides an important data related to humerus features and its utility in sex differentiation. All the humeri were dry, free of damage or deformity and were fully ossified. The instruments used for the measurements of various parameters of the humerus were: scale, sliding vernier calliperosteometer, scientific balance and weight, standardised and flexible steel tape, non-elastic threads, marker pencils and pens.

\section{Following measurement were taken:}

Total Length (L): The functional length of the humerus, i.e., the distance between the upper and lower end in anatomical position was recorded with the help of osteometer and the length was recorded in $\mathrm{mm}$. The midpoint of the shaft was marked simultaneously. It may also be called as maximal length

Weight (W): Weight of each dried humerus was recorded with the help of scientific balance and weight. It was recorded in grams.

Vertical diameter of head: This is the maximum diameter of the head in the vertical plane (coronal), it was measured with the help of vernier calliper in $\mathrm{mm}$

Transverse diameter of head: This is the maximum diameter of the head, in the transverse plane of the head of the humerus. It was also measured by vernier calliper, in $\mathrm{mm}$.

Circumference of midshaft (mSC): It was measured with the help of non-elastic thread at the midpoint of the shaft by the procedure as for the other circumferences. Length of the thread was measured on the scale, in $\mathrm{mm}$

Length of the Shaft of humerus: It is measured between two lines; upper and lower. Upper line was drawn at a distance of $1 \mathrm{~cm}$ below the lowest point on articular margin of head; this point was in line with medial epicondyle.

Circumference of head at Anatomical neck (CA): The circumference of anatomical neck of humerus was measured by marking a fixed point at groove opposite the Greater tubercle on anatomical neck with a marker pencil and running the non-elastic thread along the groove starting from the fixed point and back to it. The length of thread then recorded on scale in $\mathrm{mm}$.

Circumference of Surgical neck: It was measured at a point $1 \mathrm{~cm}$ below the lowest point on margin of articular surface of head of humerus; It was measured with the help of nonelastic thread by same method as that of CA. 
Maximum Width of upper end of humerus: It was recorded by placing the upper end of humerus transversely with lesser tubercle facing upwards in osteometer and recording the distance shown on osteometer scale in $\mathrm{mm}$.

Width of Bicipital groove: It was the distance between two lips of biciptal groove measured at the level of surgical neck with the help of verniercalliper.

Anteroposterior diameter of midshaft:The anteroposterior distance of midshaft of humerus is measured at the level of midpoint of shaft with the help of vernier caliper in $\mathrm{mms}$.

Transverse diameter of midshaft of humerus: The maximum transverse diameter of midshaft is measured at midshaft point by holding humerus in anatomical position by vernier calliper in $\mathrm{mm}$.

Bi-epicondylar distance: Distance between two epicondyles of lower end of humerus is measured with the help of vernier calliper in $\mathrm{mm}$.

Trochlear Width: It was measured by vernier calliper as anteroposterior width of trochlea at medial margin of medial flange of trochlea, recorded in $\mathrm{mm}$.

Capitulum Width: It was measured as maximum anteroposterior distance of capitulum. It was recorded in $\mathrm{mm}$ on vernier calliper scale with limbs of vernier calliper parallel to humerus.

Width of Articular Surface of lower end of humerus: It was measured with vernier calliper as a maximum width of articular surface at lower end of humerus.

Height of medial Flange of trochlea: It was measured with the help of vernier calliper as maximum length of medial flange of trochlea on inferior aspect.

Circumference of Shaft distal to deltoid tuberosity (Cdt): It was measured at a point $1 \mathrm{~cm}$ distal to midshaft point with same method as above. It was also defined as second one-third portion of the humeral diaphysis, distal to deltoid tuberosity (minimum circumference).

Trochlear distance: The measurement from the location of the known minimum circumference to the trochlea. It was measured with the help of non-elastic thread, the length of which was measured on scale.

Int J Anat Res 2019, 7(2.3):6668-73. ISSN 2321-4287
Distance of Articular margin from the Apex of greater tubercle (L1N): It was measured with the help of vernier calliper as a distance between highest point on greater tubercle and nearest point on articular margin.

Distance between the nearest Point of margin of lessertubercle and Articular margin of head (12n): It was measured with the help of vernier calliper as distance between nearest point on lesser tubercle and articular margin.

length index (li): This was obtained by dividing the functional length with the length of shaft.

Length Index (LI) = Functional length (L)/Length of shaft

Circumference (Ci): This was obtained by dividing the circumference of anatomical neck with the circumference of mid shaft.

Circumference Index $(\mathrm{Cl})=$ Circumference of shaft of the humerus.s

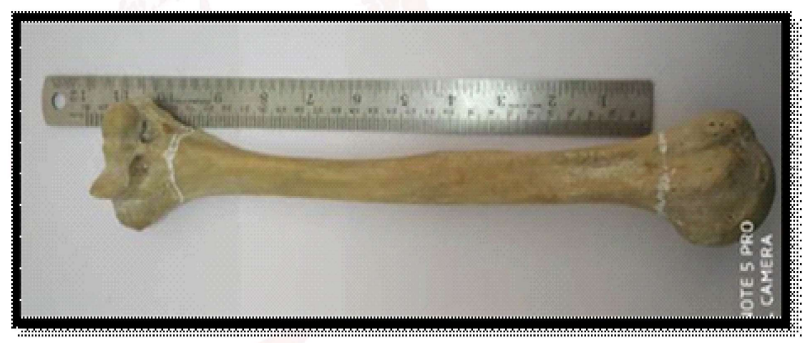

\section{RESULTS}

A total 102 Adult humerus 64 Male and 38 Female were studied in present study.Twenty five measurements were taken from each humerus.The accuracy rate for sex determination by discriminant analysis using the five parameters i.e., weight, total length, vertical diameter of head, transverse diameter of the head and the circumference of midshaft of the humerus.

Table 1:Weight of humerus.

\begin{tabular}{|c|c|c|c|}
\hline Gender & Mean (g) & SD & P value \\
\hline Male (64) & 102.22 & \pm 18.36 & \multirow{2}{*}{$<0.001$} \\
\hline Female (38) & 86.24 & \pm 14.21 & \\
\hline
\end{tabular}

As shown in table 1 the weight of male humerus is more then female.

Table 2:Length of humerus.

\begin{tabular}{|c|c|c|c|}
\hline Gender & Mean (mm) & SD & p value \\
\hline Male (64) & 311 & \pm 15.24 & \multirow{2}{*}{$<0.001$} \\
\hline Female (38) & 274 & \pm 16.85 & \\
\hline
\end{tabular}

As shown in table 2, the length of male humerus is more then female. 
Table 3:Vertical and transverse diameter of head of humerus.

\begin{tabular}{|c|c|c|c|c|c|}
\hline \multirow{2}{*}{ Gender } & \multicolumn{2}{|c|}{ Vertical diameter } & \multicolumn{2}{c|}{ Transverse diameter } & \multirow{2}{*}{ p value } \\
\cline { 2 - 5 } & Mean (mm) & SD & Mean (mm) & SD & \\
\hline Male (64) & 42.26 & \pm 2.05 & 39.85 & \pm 1.99 & \multirow{2}{*}{$<0.001$} \\
\hline Female (38) & 38.54 & \pm 2.54 & 34.01 & \pm 2.28 & \\
\hline
\end{tabular}

As shown in table 3, the vertical and transverse diameter of humerus in male is more then female.

Table 4:Various measured humerus parameters.

\begin{tabular}{|l|c|c|c|c|c|}
\hline \multirow{2}{*}{ Parameters } & \multicolumn{2}{|c|}{ Male (64) $\mathrm{mm}$} & \multicolumn{2}{c|}{ Female (38) $\mathrm{mm}$} & \multirow{2}{*}{ p value } \\
\cline { 2 - 6 } & Mean & SD & Mean & SD & \\
\hline Midshaft of humerus & 59.26 & 3.62 & 54.21 & 4.05 & $<0.001$ \\
\hline Length of shaft & 236.22 & 11.65 & 219.1 & 13.85 & $<0.001$ \\
\hline Circumference of head at anatomical neck & 130.45 & 6.1 & 114.84 & 7.74 & $<0.001$ \\
\hline Circumference of surgical neck & 90.65 & 6 & 79.54 & 6.85 & $<0.001$ \\
\hline Maximum width of upper end & 47.88 & 3.44 & 41.21 & 3.41 & $<0.001$ \\
\hline Anterioposterior diameter of mid shaft & 19.01 & 1.27 & 17.04 & 1.65 & $<0.001$ \\
\hline Transverse diameter of midshaft & 18.16 & 1.05 & 15.81 & 0.98 & $<0.001$ \\
\hline Width of bicipital groove & 10.09 & 1.28 & 8.94 & 1.25 & $<0.001$ \\
\hline Bi-Epicondylar distance & 58.89 & 3.74 & 51.85 & 4.01 & $<0.001$ \\
\hline Trochlear Width & 23.84 & 1.28 & 20.88 & 1.46 & $<0.001$ \\
\hline Capitulum Width & 22.25 & 1.02 & 20.68 & 1.65 & $<0.001$ \\
\hline Width of articular surface of lower end & 40.09 & 2.1 & 35.1 & 2.51 & $<0.001$ \\
\hline Height of medial flange of trochlea & 7.25 & 1.05 & 8.21 & 1.26 & $<0.001$ \\
\hline $\begin{array}{l}\text { Circumference of Shaft distal to deltoid } \\
\text { tuberosity }\end{array}$ & 59.85 & 3.41 & 52.1 & 4.27 & $<0.001$ \\
\hline Trochlear distance & 124.8 & 14.2 & 114.2 & 7.8 & $<0.001$ \\
\hline $\begin{array}{l}\text { Distance of Articular margin from the Apex } \\
\text { of greater tubercle }\end{array}$ & 10.19 & 1.24 & 9.47 & 2.14 & $<0.001$ \\
\hline $\begin{array}{l}\text { Distance between the nearest Point of } \\
\text { margin of lesser tubercle and Articular } \\
\text { margin of head }\end{array}$ & 18.65 & 1.24 & 18.05 & 1.92 & $<0.001$ \\
\hline Length index & 2.34 & 0.15 & 2.09 & 0.84 & $<0.001$ \\
\hline Circumflex index & & & & & \\
\hline
\end{tabular}

As shown in table 4 all measures parameters related with humerus were higher in male compared with female.

\section{DISCUSSION}

It is an established fact that, standard metrical values derived for sexing the skeletal in one region if applicable to the other region may not give $100 \%$ accuracy.

Therefore it is imperative to obtain standard metrical values which are specific to a region. In the present study 102 Adult humerus 64 Male and 38 Female were studied to obtain the standard metrical values in the central Gujarat region.The metric values of all parameters were higher in males as compared to females in the present studied humeri. Research from India and other parts of the world also reflects that the dimensions of the humerus are larger in males as compared to females.
Table 5:Comparison findings of length of humerus of present study with other study.

\begin{tabular}{|c|c|c|}
\hline Authors & $\begin{array}{c}\text { Male } \\
\text { Mean (mm) }\end{array}$ & $\begin{array}{c}\text { Female } \\
\text { Mean (mm) }\end{array}$ \\
\hline Present study & 311 & 274 \\
\hline Shaikh Siraj Ahmed et al [20] & 312 & 283 \\
\hline Reddy BB et al [21] & 310.79 & 278.15 \\
\hline Anil kumar reddy et al [22] & 310 & 260 \\
\hline
\end{tabular}

In the present study, the Maximum length of humerus is highly significant parameter there is a considerable amount value difference is found between males and females. Our findings are in conformity with the findings reported by Singh S (1972) [23], DeryaAtamturk, (2010) [24] and Iscan M.Y et al (1998) [25], andGirish patil (2011) [26] study on south Indians, show statistically significant sex differences between 
mean of Maximum length in males and female. Soni $\mathbf{G}$ et al., study conducted on $\mathbf{4 0}$ male and 40 female right humeri measured six parameters. The mean values of five out of these six measurements were significantly lower in females as per results of univariate analysis. The combination of parameters of vertical head diameter of the shaft and epicondylar width provided $85 \%$ accuracy in male and $90 \%$ accuracy in female humerus bones [26].

The trochlear width in present study was $23.84 \pm 1.28 \mathrm{~mm}$ in males and $20.88 \pm 1.46 \mathrm{~mm}$ in females; anatomical neck circumference in males was $130.45 \pm 6.10 \mathrm{~mm}$ and in females was $114.84 \pm 7.74 \mathrm{~mm}$ and the BED in males was $58.89 \pm 3.75$ and $51.85 \pm 4.01 \mathrm{~mm}$ in females. The study by Shaikh Siraj Ahmed et al was $24.56 \pm 1.39$ $\mathrm{mm}$ in males and $21.22 \pm 1.71 \mathrm{~mm}$ in females; anatomical neck circumference in males was $131.83 \pm 6.15 \mathrm{~mm}$ and in females was $115.2 \pm 7.88$ $\mathrm{mm}$ and the BED in males was $59.95 \pm 3.45$ and $52.57 \pm 4.36 \mathrm{~mm}$ in females ${ }^{20}$. The study by Reddy $B$ and Doshi MA reported similar trochlear width of $24.70 \pm 1.12 \mathrm{~mm}$ in males and $20.96 \pm 1.58 \mathrm{~mm}$ in females; the anatomical neck circumference reported in males was $131.27 \pm 5.51 \mathrm{~mm}$ and in females was $112.78 \pm 8.07 \mathrm{~mm}$; the BED in males was $60.5 \pm 3.05 \mathrm{~mm}$ and $52.17 \pm 3.78 \mathrm{~mm}$ in females [21].

Thus, the present data regarding humerus measurements described are in line with literature from Indian population with differences in humerus measurements data from other continent populations. The difference in measurements across different population groups has been attributed to difference in diet patterns, genetic differences and environmental factors affecting the growth patterns [28]. Multivariate analysis with similar parameters has been found to be able to differentiate male and female humerus bones with reasonable accuracy in different population groups.

\section{Conflicts of Interests: None}

\section{REFERENCES}

[1]. KrogmanWM.Skeleton in Forensic Medicine.proc instmed.1946;16:p154-167.

[2]. Mall G, Hubig M, Bu“ tter A, Kuznik J, Penning R, Graw M. Sexdetermination and estimation of stature from the long bones of thearm. Forensic Sci Int 2001;117:23-3
[3]. Steyn M, Is_can MY. Osteometric variation in the humerus: sexual dimorphism in South Africans. Forensic Sci Int 1999;106:77-85.

[4]. Sakaue K. Sexual determination of long bones in recent Japanese.Anthropol Sci 2004;112:75-81.

[5]. Frutos R. Metric determination of sex from the humerus in a Guatemalan forensic sample. Forensic Sci Int 2005;147:153-7.

[6]. Nidugala H, Bhargavi C, Avadhani R, Bhaskar B. Sexual dimorphism of the craniofacial region in a South Indian population.Singapore Med J 2013;54:458-62.

[7]. Akhlaghi M, Khalighi Z, Vasigh S, Yousefinejad V. Sex determination using mandibular anthropometric parameters in subadult Iranian samples. J Forensic Leg Med 2014;22:150-3.

[8]. Albanese J. A method for estimating sex using the clavicle,humerus, radius, and ulna. J Forensic Sci 2013;58:1413-9.

[9]. Akhlaghi M, Sheikhazadi A, Ebrahimnia A, Hedayati M, Nazparvar B, Saberi Anary SH. The value of radius bone in prediction of sex and height in the Iranian population. J Forensic Leg Med 2012;19:21922.

[10]. Krishan K, Kanchan T, Asha N, Kaur S, Chatterjee PM, Singh B.Estimation of sex from index and ring finger in a North Indian population. J Forensic Leg Med 2013;20:471-9.

[11]. Barrett CK, Case DT. Use of 2D:4D digit ratios to determine sex.J Forensic Sci 2014;59:1315-20.

[12]. Krishan K, Kanchan T, Passi N, DiMaggio JA. Sexual dimorphism in foot length ratios among North Indian adolescents. J Forensic Leg Med 2015;36:96101.

[13]. Hayashizaki Y, Usui A, Hosokai Y, Sakai J, Funayama M. Sex determination of the pelvis using Fourier analysis of postmortem CT images. Forensic Sci Int 2015;246:122.e1-9.

[14]. Karakas HM, Harma A, Alicioglu B. The subpubic angle in sex determination: anthropometric measurements and analyses on Anatolian Caucasians using multidetector computed tomography datasets. J Forensic Leg Med 2013;20:1004-9.

[15]. Kranioti EF, Bastir M, Sa' nchez-Meseguer A, Rosas A. A geometric-morphometric study of the cretan humerus for sex identification. Forensic Sci Int 2009;189:111.e1-8.

[16]. Kanchan T, Krishan K, Sharma A, Menezes RG. A study of correlation of hand \& foot dimensions for personal identification in mass disaster. Forensic Sci Int 2010;199:112.e1-6.

[17]. Russo EG. Sex determination from the talus and calcaneus measurement. Forensic Sci Int 2007;171:151-6.

[18].Elena FK, Markas B, Andrea SM, Antonio R. A geometrc-morphometric study of the Cretan humerus for sex identification. Forensic Sci Int 2009;189(1-3): 111 e1-e8.

[19]. Krishna G. BD Chaurasia's Hand Book of General Anatomy. Blood supply of bones. 4th ed 2011. CBS Publishers and Distributors Pvt. Ltd 43-44. 
[20]. Shaikh shiraj Ahmed, Faiza Banu Siddiqui, Sujatha Banglore Bayer. Sex differentiation of humerus an osteometric study. Journal of Clinical and Diagnostic Research, 2018. Dec;12(12):AC01-AC05

[21]. Reddy BB, Doshi MA. Sex determination from adult human humerus by discriminant function analysis. Int J Res Med Sci. 2017;5:3891-97.

[22]. Anil Kumar Reddy Y, Sheela Grace Jeevamani, Indira Vijay Ingole, Raghavendra. A Study on sexual dimorphism of the humerus in Tamilnadu region. International journal of medical research health science. 2014;3(1):43-46.

[23]. Singh S, Singh SP. Identification of sex from the humerus. Indian Journal of Medicine and Research. 1972;60:1061-66.

[24]. Derya Atamturk, M. Akif Akcal, Izzet Duyar and Nuket Mas. Sex estimation from the radiographic measurements of the humerus. Eurasian J. Anthropol. 2010;1(2): 99-108.
[25]. Iscan MY. Forensic Anthropology around the world. For. Scl. Inter. 1998;74: 1-3.

[26]. Girish patil, Sanjeev Kolagi, Umesh Ramadurg. Sexual dimorphism in the Humerus: South Indians. Journal of clinical and Diagnostic Research. 2011;5(3): 538-41.

[27]. Soni G, Dhall U, Chhabra S. Determination of sex from humerus: discriminant [analysis. Australian Journal of Forensic Sciences. 2013; 45(2):147-52.

[28]. Singh A, Nagar M, Kumar A. An anthropometric study of the humerus in adults. Research \& Reviews: Journal of Medical and Health Sciences. 2014;3(3):7782.

How to cite this article:

Hetal V. Vaishnani, A.R.Gandotra, G.V.Shah. A STUDY ON SEXUAL DIMORPHISM OF THE HUMERUS IN CENTRAL GUJARAT. Int J Anat Res 2019;7(2.3):6668-6673. DOI: 10.16965/ijar.2019.200 